\section{RNAs actively cycle on the Sm-like protein Hfq}

\author{
Aurélie Fender, ${ }^{1}$ Johan Elf, ${ }^{1,2}$ Kornelia Hampel, ${ }^{3}$ \\ Bastian Zimmermann, ${ }^{3}$ and E. Gerhart H. Wagner ${ }^{1,2,4}$
}

${ }^{1}$ Department of Cell and Molecular Biology, Biomedical Center, Uppsala University, SE-75124 Uppsala, Sweden; ${ }^{2}$ Science for Life Laboratory, SE-75124 Uppsala, Sweden; ${ }^{3}$ Biaffin GmbH \& Co. KG, D-34132 Kassel, Germany

Hfq, a protein required for small RNA (sRNA)-mediated regulation in bacteria, binds RNA with low-nanomolar $K_{d}$ values and long half-lives of complexes (>100 min). This cannot be reconciled with the 1-2-min response time of regulation in vivo. We show that RNAs displace each other on Hfq on a short time scale by RNA concentrationdriven (active) cycling. Already at submicromolar concentrations of competitor RNA, half-lives of RNA-Hfq complexes are $\approx 1 \mathrm{~min}$. We propose that competitor RNA associates transiently with RNA-Hfq complexes, RNAs exchange binding sites, and one of the RNAs eventually dissociates. This solves the "strong binding-high turnover" paradox and permits efficient use of the Hfq pool.

Supplemental material is available at http://www.genesdev.org.

Received April 29, 2010; revised version accepted September $28,2010$.

The Escherichia coli protein Hfq, identified as a host factor required for replication of bacteriophage $\mathrm{Q} \beta$ (Franze de Fernandez et al. 1968), is conserved and contains the Sm motif typical of eukaryotic Sm and Lsm proteins. Hfq tightly binds RNA with relaxed specificity. When absent, bacteria show pleiotropic effects that can be attributed to Hfq's function in bacterial small RNA (sRNA) regulation of gene expression (Romby et al. 2006; Brennan and Link 2007; Waters and Storz 2009). Numerous Hfq-sRNA and Hfq-mRNA interactions have been validated in largescale screens (Zhang et al. 2003; Sittka et al. 2008) and studied in detail (Geissmann and Touati 2004; Vecerek et al. 2010). Hfq can increase sRNA-target RNA association rates (Soper and Woodson 2008), stabilize sRNAs (Urban and Vogel 2007), and act as a chaperone by unfolding of an sRNA or mRNA structure (Geissmann and Touati 2004).

The homohexameric $\mathrm{Hfq}$ ring displays two faces: proximal and distal. Hfq-RNA interactions show a preference of U-rich for proximal and A-rich RNA sequences for distal face binding (de Haseth and Uhlenbeck 1980a; Mikulecky et al. 2004). Simultaneous binding may occur on both sides as well, which could facilitate intermolecular base-pairing and regulation (Rajkowitsch and Schroeder 2007).

[Keywords: Hfq; sRNA; antisense RNA; post-transcriptional regulation; RNA chaperone; Lsm protein]

${ }^{4}$ Corresponding author.

E-MAIL gerhart.wagner@icm.uu.se; FAX 46-18-530396.

Article is online at http://www.genesdev.org/cgi/doi/10.1101/gad.591310.
Structures of Hfq from E. coli, Staphylococcus aureus, and Pseudomonas aeroginosa have been determined by X-ray crystallography (Schumacher et al. 2002; Sauter et al. 2003; Nikulin et al. 2005). Two cocrystal structures support two distinct binding surfaces: In $S$. aureus Hfq, $\mathrm{AU}_{5} \mathrm{G}$ RNA is bound around the inner rim of the proximal face (Schumacher et al. 2002), and E. coli Hfa has oligo-A bound on the distal face (Link et al. 2009).

This study addresses the question of how stable HfqRNA binding can be reconciled with Hfq's function in sRNA-mediated regulation in vivo. Many RNAs bind tightly to $\mathrm{Hfq}$, with $\mathrm{K}_{\mathrm{d}}$ values ranging from sub- to midnanomolar (Arluison et al. 2004; Geissmann and Touati 2004; Lease and Woodson 2004; Mikulecky et al. 2004; Sittka et al. 2008; Soper and Woodson 2008; Hopkins et al. 2009; Holmqvist et al. 2010). Thus, if binding-competent RNAs were in molar excess, almost all Hfq would be bound to RNAs. Hfq-RNA dissociation rate constants in vitro are too low to be compatible with a biologically relevant time scale; half-lives of complexes are in the range of a generation time. If newly induced sRNAs only could access free $\mathrm{Hfq}$ after its dissociation from bound RNAs, their activity should be severely delayed. Yet, the time frame from induction of an sRNA to a significant regulatory effect is short (1-2 min) (Massé et al. 2003), and hence sRNAs can acquire Hfq rapidly. This highlights a paradox, with Hfq being tightly sequestered by the intracellular pool of RNAs, contrasted by the need of new sRNAs to rapidly access Hfq. We considered here a conventional cycling model (dissociative/passive) (Fig. 1A) and associative/active cycling (Fig. 1B). In model A, newly synthesized RNA (Fig. 1A, in red) can only bind Hfq after the resident RNA (Fig. 1A, in blue) has dissociated; i.e., the rate of binding of the incoming RNA is limited by the Hfq-RNA dissociation rate constant and is not affected by the concentration of the free RNA. In model B, free RNA transiently binds the Hfq-RNA complex, whereupon one of the RNAs eventually dissociates. Thus, the dissociation rate of the bound RNA is a function of the concentration of the free RNA (Fig. 1B). This would render cycling much more rapidly, and the intracellular pool of binder RNAs would rapidly equilibrate on Hfq. The two models are distinguishable, since the RNA exchange in model $\mathrm{A}$ is limited by the dissociation rate constant of Hfq-RNA, whereas exchange in model B increases in proportion to the free RNA concentration.

\section{Results and Discussion}

\section{$H f q$ binds model sRNAs and mRNAs with high affinity}

We chose six RNAs from E. coli to determine their binding characteristics, using three different approaches. These were MicA, MicC, and MicF, and their targets, $o m p A, o m p C$, and $o m p F$ mRNA. Their regulatory interactions are known, as is their Hfq dependence in vivo (Andersen and Delihas 1990; Chen et al. 2004; Rasmussen et al. 2005; Udekwu et al. 2005).

RNA binding at increasing concentrations of $\mathrm{Hfq}_{6}$ (hexameric $\mathrm{Hfq}$ is $\mathrm{Hfq}_{6}$ throughout this paper) at $37^{\circ} \mathrm{C}$ was assayed by gel-shift analysis. Supplemental Figure S1 indicates tight $\mathrm{Hfa}_{6}-\mathrm{RNA}$ binding, with $\mathrm{K}_{\mathrm{d}}$ values ranging from 0.9 to $4 \mathrm{nM}$ (Table 1). Binary $\mathrm{Hfq}_{6}-\mathrm{RNA}$ complexes were formed first, and supershifted complexes 


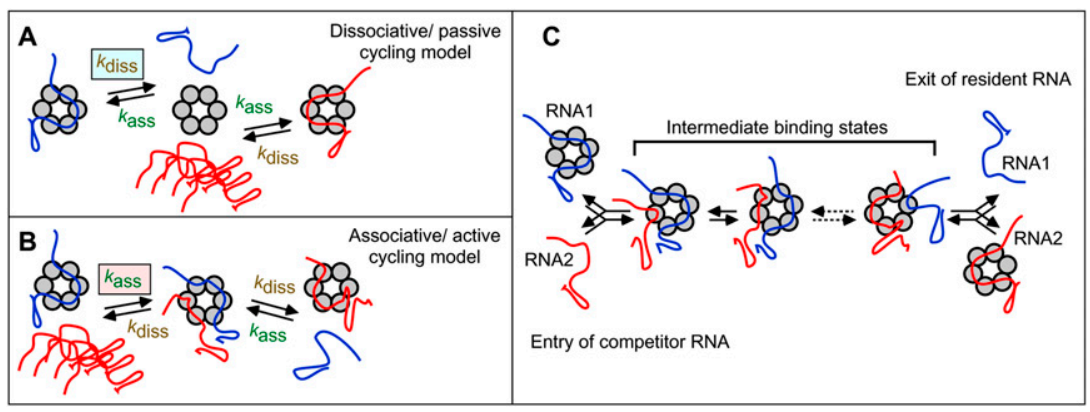

Figure 1. Passive and active models for RNA cycling on Hfq. The passive $(A)$ and active $(B)$ cycling models are explained in the text. $(C)$ More detailed schematics of RNA exchange on $\mathrm{Hfq}$, highlighting its reversibility. Some intermediate binding states are indicated and differ by subsite occupancy. For simplicity, dissociation is assumed to always occur from a single site-bound state.

appeared at higher Hfq concentrations (Supplemental Fig. S1). The $\mathrm{K}_{\mathrm{d}}$ values of RNA-Hfq complexes are often subnanomolar (e.g., Geissmann and Touati 2004; Sittka et al. 2008) to mid-nanomolar (e.g., Lease and Woodson 2004; Mikulecky et al. 2004). For MicA and ompA RNA, additional methods were used for comparison. Surface plasmon resonance (SPR) was employed to assess binding kinetics of either MicA or $\operatorname{ompA}$ RNA to Hfq. $\mathrm{K}_{\mathrm{d}}$ values and association and dissociation rate constants were calculated (Supplemental Fig. S2). The association rate constant $k_{\mathrm{a}}$ for both RNAs was $\approx 10^{6} \mathrm{M}^{-1} \mathrm{sec}^{-1}$, and the dissociation rate constants $k_{\mathrm{d}}$ were $3 \times 10^{-4} \mathrm{sec}^{-1}$ to $6 \times$ $10^{-4} \mathrm{sec}^{-1}$ (Supplemental Table S1).

We then used nitrocellulose filter binding to determine dissociation rates and assess competition. MicA* or ompA $\mathrm{RNA}^{\star}$ (asterisk indicates labeled RNA) was incubated with increasing concentrations of $\mathrm{Hfq}_{6}$, and retention of bound RNA ${ }^{\star}$ was monitored. This gave $\mathrm{K}_{\mathrm{d}}$ values of $1.7 \pm$ $0.1 \mathrm{nM}$ (MicA-Hfq $\mathrm{H}_{6}$ ) and $1.5 \pm 0.5 \mathrm{nM}$ (ompA-Hfa $\mathrm{q}_{6}$ ), similar to values obtained by gel shift and SPR (Table 1).

In these assays, MicA-Hfa 6 binding was essentially complete before $20 \mathrm{sec}$ at the concentrations used (1 nM $\mathrm{MicA}^{\star}$ or ompA $\mathrm{RNA}^{\star}, 10 \mathrm{nM} \mathrm{Hfq}{ }_{6}$ ). Dissociation was measured by preforming MicA ${ }^{\star}-\mathrm{Hfq}_{6}$ or ompA RNA*$\mathrm{Hfq}_{6}$ complexes, followed by $>250$-fold dilution and filtering after a further incubation for different time periods at $37^{\circ} \mathrm{C}$. Both $\mathrm{MicA}-\mathrm{Hfq}_{6}$ and $\mathrm{ompA}-\mathrm{Hfq}_{6}$ complexes dissociated slowly, at $k_{\mathrm{d}}$ values of $\approx 0.7 \times 10^{-4} \mathrm{sec}^{-1}$ (Table 1). This corresponds to half-lives of $>150 \mathrm{~min}$.

\section{RNAs promote concentration-dependent dissociation of $\mathrm{Hfq}$-bound RNA}

By filter binding, we asked whether unlabeled competitor RNA in high excess could promote faster dissociation of RNA * from complexes with Hfq. Figure 2, A and B, shows time courses of dissociation. In addition to the RNAs mentioned above, RNA $-\mathrm{Hfq}_{6}$ was challenged by IstR-1 (Darfeuille et al. 2007), poly-U, and poly-A. Competitor RNA $(0.75 \mu \mathrm{M})$ was added to $0.75 \mathrm{nM} \mathrm{RNA}^{\star}-\mathrm{Hfq}_{6}$ complexes, incubated for the times indicated, and filtered. All Mic RNAs, poly-U, ompC, and ompA RNA, caused rapid dissociation of $\mathrm{MicA}^{\star}$ from $\mathrm{Hfq}$ (Fig. 2A), with $>50 \%$ release within 2-5 min. IstR-1, a poor Hfq binder, had no significant effect, and neither did $o m p F$ RNA and poly-A. Similarly, rapid dissociation of $\operatorname{omp} A$ RNA * from Hfq was induced by all RNAs but IstR-1 (Fig. 2B). Note that, although ompF RNA and poly-A failed to compete with MicA* (Fig. 2A), they did dissociate $\operatorname{ompA} \mathrm{RNA}^{\star}$ (Fig. 2B), likely indicating differences in face preference.

The chaser RNA concentration dependence of dissociation was measured by competition experiments on $\mathrm{RNA}^{\star}-\mathrm{Hfq}_{6}$ complexes (Fig. 2C,D). The dissociation rates of $\mathrm{RNA}^{*}-\mathrm{Hfq}$ complexes increased as a function of competitor RNA concentration, and half-lives of RNA ${ }^{\star}-\mathrm{Hfq}$ complexes decreased from $>150 \mathrm{~min}$ (absence of chaser) to $\approx 1 \mathrm{~min}$ (highest concentrations of chaser RNAs) (Table 1). These results are incompatible with model A (Fig. 1A) and show that RNAs drive dissociation of RNA ${ }^{\star}-\mathrm{Hfq}_{6}$ complexes much faster than expected from the first-order dissociation rate constants determined in the absence of competitor.

Since RNA ${ }^{\star}-\mathrm{Hfq}$ dissociation rates are a function of chaser RNA concentration, the reaction is second order. At the high molar excess of chaser used, the reaction follows pseudo-first-order kinetics. Second-order rate constants can be estimated by plotting the apparent $k_{\mathrm{d}}$ against the concentration of chaser RNA (Supplemental Fig. S3); initial slopes of the curves reflect the association rate of competitor RNA to RNA*-Hfq complexes. The plateaus indicate saturation of binding and a slow rearrangement of RNAs on Hfq before one of them dissociates (see below).

\section{Displacement of $\mathrm{Hfq}$-bound RNAs involves at least two steps}

The competitor concentration dependence (Fig. 2C,D; Table 1) can be approximated with straight lines in the lin-log graphs. There are, however, deviations from the assumption of pseudo-first-order kinetics: (1) an initial delay in the decay curves, (2) dissociation rates saturate at micromolar concentrations of competitor, and (3) Hfqbinding plateaus at a nonzero value (Supplemental Fig. S4C). We developed a mathematical model of the RNA exchange mechanism in which the competitor RNA binds the stable Hfq-RNA* complex in a second-order reaction (Supplemental Fig. S4). The initially weakly bound RNA can either dissociate rapidly or gradually displace strongly bound RNA * in a series of reversible firstorder reactions. When $\mathrm{RNA}^{\star}$ reaches its weakly bound state, it either dissociates or reverts into a more stably bound conformation. This kinetic model accurately reproduces all aspects of the chase experiment. In particular, the intrinsic consecutive displacement steps limit how fast Hfq can cycle, and explain the initial delay in the dissociation curves and the saturation at high competitor concentration. The nonzero plateau levels reflect the equilibrium binding of RNA * to Hfq, which shows that Hfq does not drive exchange irreversibly in one direction.

The kinetic parameters that fitted the experimental data to the model give quantitative insights into the mechanism; i.e., when MicA RNA ${ }^{\star}$ is in the weakly bound state, it dissociates from Hfq at a rate of $0.06 \mathrm{sec}^{-1}$. However, in the absence of competitor, it only spends $<1 \%$ of its time in this state, resulting in an overall dissociation rate of $<10^{-4} \mathrm{sec}^{-1}$ (Supplemental Fig. S4). Thus, the chaser RNA concentration dependence supports an active exchange model (Fig. 1B): The release of the resident RNA 


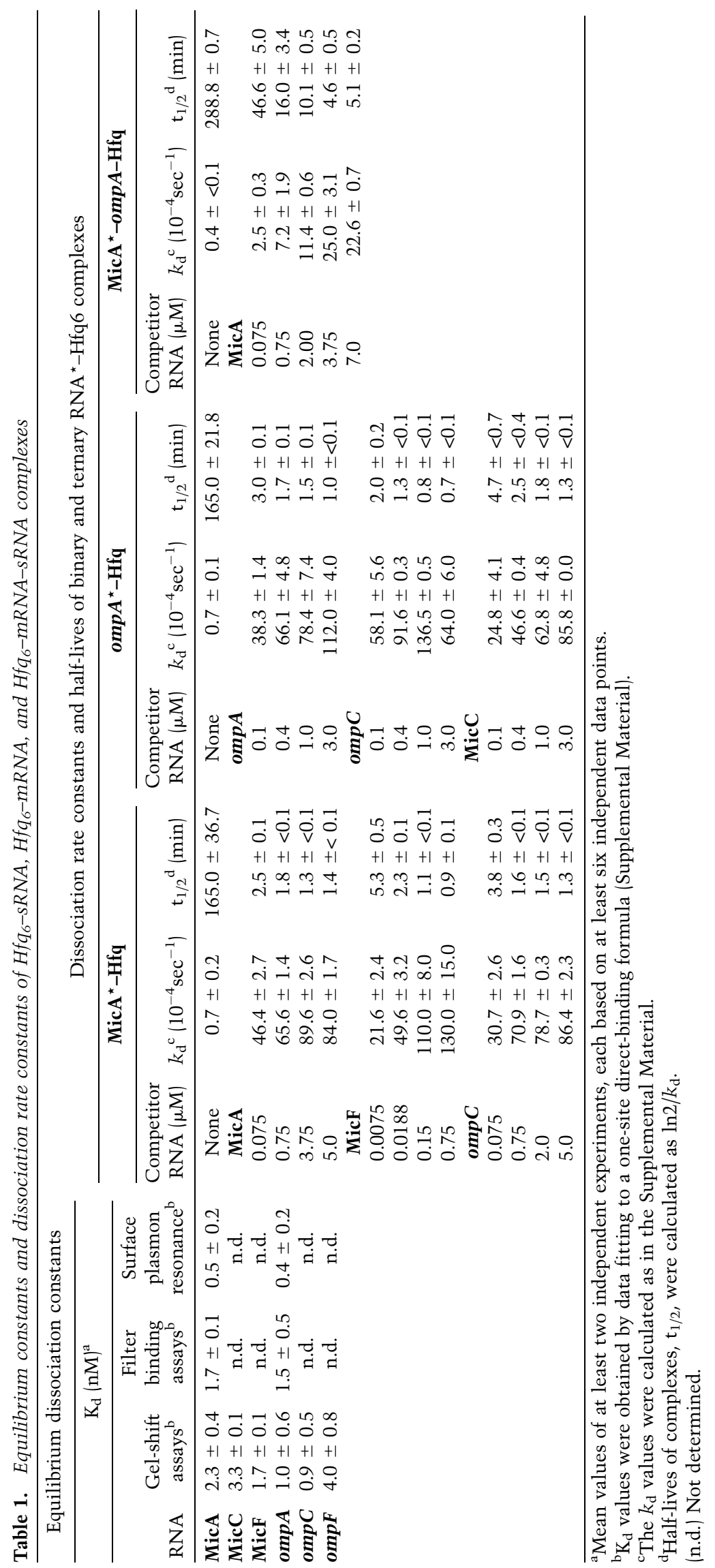




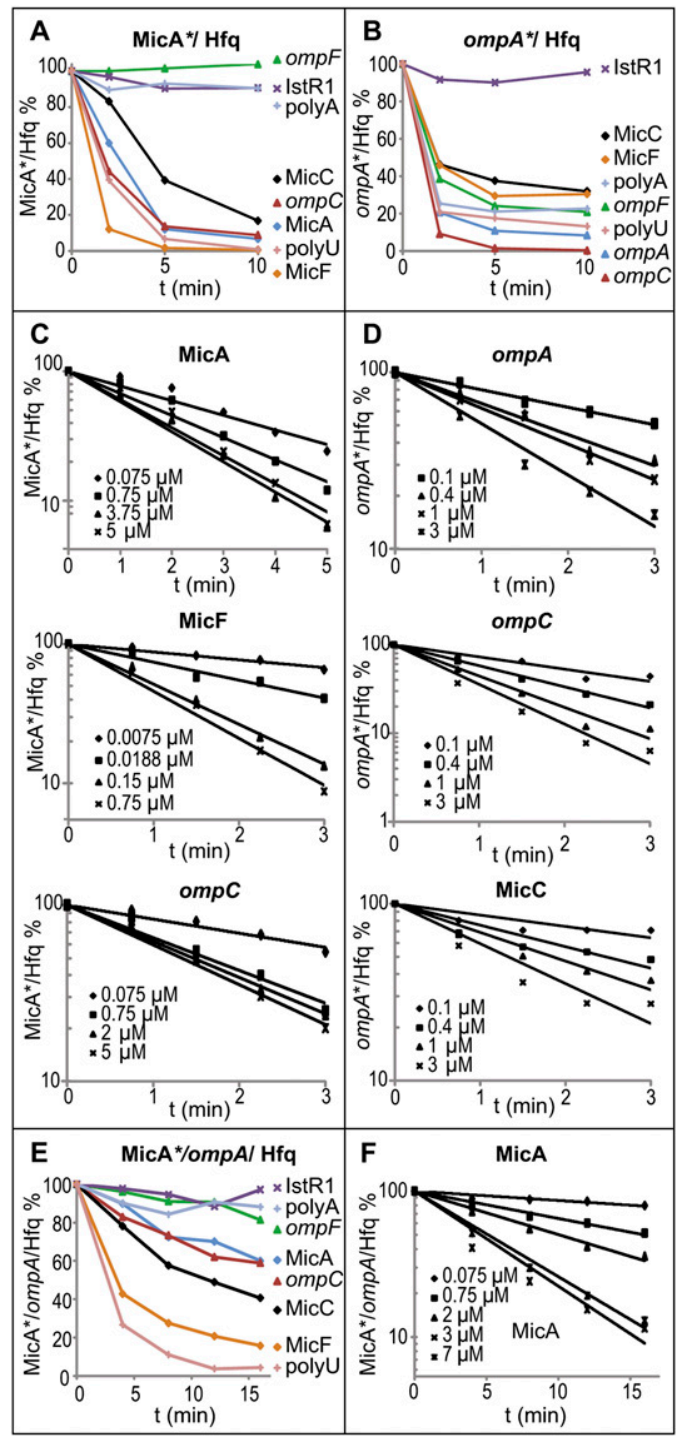

Figure 2. Competitor RNA-driven dissociation of MicA-Hfq, ompA RNA-Hfq, and MicA-ompA RNA-Hfq complexes. Filter binding assays were performed as described. $\mathrm{MicA}^{\star}-\mathrm{Hfq}(A)$ or ompA $\mathrm{RNA}^{*}$-Hfq $(B)$ complexes were preformed $(0.75 \mathrm{nM}$ RNA/7.5 nM $\mathrm{Hfq}_{6}$ ) and competed by adding a 1000-fold excess of unlabeled RNAs. The graphs show the retention of labeled RNA by Hfq as a function of time, using the competitor RNAs indicated. $(C, D)$ Competition of MicA*-Hfq by MicA, MicF, and ompC RNA $(C)$, and of ompA* RNAHfq by ompA RNA, ompC RNA, and $\operatorname{MicC}(D)$, except that competitor RNA was added at the concentrations indicated. $(E)$ MicA*-ompA

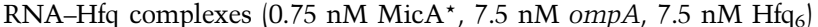
were competed as in $A$ and $B$. $(F)$ Competition as a function of MicA concentration was analyzed as in $C$ and $D$. The dissociation rate constants and half-lives of complexes are shown in Table 1.

is driven by association of other (or the same kind of) RNAs in a concentration-dependent manner. Based on published structures, the Hfq hexamer has six identical binding sites on each surface. High affinity is obtained by contacts at multiple binding sites (Link et al. 2009), as also seen for protein chaperones (Randall and Hardy 1995). $\mathrm{Hfq}_{6}-$ RNA complexes represent an ensemble of binding states (from one to six site occupancy). Competitor RNA gains initial access to only one transiently unoccupied subunit (Fig. 1C), and dissociation of the resident RNA occurs from a state in which only one monomer-RNA contact remains. We envision several binding intermediates with different subsite occupancies for the two RNAs that are simultaneously present on $\mathrm{Hfq}_{6}$. Stepwise exchange of RNA elements on Hfq subunits involves low $\Delta \Delta \mathrm{G}$ barriers, since binding energies of both transiently bound RNAs per site should be nearly equivalent. The observed RNA exchange is not external energy-driven (Supplemental Table S2).

In the model in Figure 1C, RNA exchange on Hfq is fully reversible, as required for a mechanism that operates at equilibrium. The high turnover of binding-competent RNAs in vivo will, however, drive the net displacement of any given RNA bound to Hfq, such that the population of bound RNAs changes with the intracellular RNA pool. Based on our results, many competitor RNAs at 100-200 $\mathrm{nM}$ will drive dissociation, and thereby exchange, from half-lives of $\approx 150 \mathrm{~min}$ to $1-2 \mathrm{~min}$, a relevant time frame in vivo. Passive cycling cannot achieve this and is limited by the first-order dissociation rate constant of RNA-Hfq (Supplemental Fig. S5).

RNA concentration-driven cycling is most effective when the total $\mathrm{Hfq}_{6}$ concentration is lower than the total concentration of Hfq-binding sites on RNAs. The sum of all Hfq binders in vivo must be a significant fraction of the entire RNA pool; deep sequencing identified $\approx 800$ Hfq coimmunoprecipitation-enriched mRNAs (Sittka et al. 2008), and many if not most sRNAs bind Hfa (Wassarman et al. 2001; Zhang et al. 2003; Sittka et al. 2008). Some individual sRNAs reach micromolar concentrations (Altuvia et al. 1997). Hfq also binds 16S rRNA (de Haseth and Uhlenbeck 1980b) and poly-A tails on mRNAs (Arluison et al. 2004), and many RNAs in E. coli carry "Hfq aptamer motifs" (Lorenz et al. 2010). Thus, the many binding-competent RNAs, even at moderate copy numbers per cell, are expected to saturate Hfq.

What are the consequences of passive or active cycling? Pulse induction of the Hfq-dependent sRNA RybB downregulates many targets. Already, at $1 \mathrm{~min}$, their mRNA levels were $<50 \%$ (Papenfort et al. 2006). If we assume an intracellular $\mathrm{Hfq}_{6}$ concentration of $\approx 1 \mu \mathrm{M}$ and a generation time of $50 \mathrm{~min}$ in the passive model, dissociation can release only a negligible fraction of $\mathrm{Hfq}$ from bound RNAs, and de novo synthesis of free $\mathrm{Hfq}_{6}$ will add the equivalent of $20 \mathrm{nM}$ within $1 \mathrm{~min}$. Thus, the induced sRNA would encounter little free Hfq. Furthermore, the sRNA needs to compete for free Hfq against a great excess of other newly synthesized RNAs and against free unbound RNAs. Thus, obtaining a significant fraction of Hfq-RybB complex, sufficient for multitarget inhibition in the time frame observed, is not plausible. Note that this conclusion is also valid at higher Hfq concentrations. In active cycling, induced RybB exchanges with bound RNAs on the entire Hfq pool and "equilibrates" in the minute range to permit a significant fraction of RybB to acquire Hfq.

The above scenarios are necessarily oversimplified. Association and dissociation rates of RNA-Hfq pairs vary. Some RNAs have strong distal or proximal face preferences, which may result in simultaneous binding of two RNAs, rather than competition (de Haseth and Uhlenbeck 1980a; Mikulecky et al. 2004; Sun and Wartell 2006; Rajkowitsch and Schroeder 2007; Vecerek et al. 2008; Link et al. 2009). In the model (Fig. 1C), we assume that each exchange occurs on one or the other face at a time and requires the presence of several identical binding sites. 
$H f q$ binds stably to, and increases the association rate of, Mic-omp mRNA complexes

The three Mic RNAs require Hfa for regulation of their targets. All matching combinations of Mic and omp RNAs were allowed to form base-paired complexes in the absence or presence of increasing concentrations of $\mathrm{Hfa}_{6}$, followed by gel-shift analysis. For all RNA pairs, ternary complexes were stable on gels and were distinguishable from RNA ${ }^{\star}-$ RNA duplexes by slower mobility (Fig. 3A; Supplemental Fig. S6A,B). When ompA-M6 mRNA, inactive in MicA binding and regulation/Udekwu et al. 2005), was used as target, ternary complexes were not formed (data not shown). Thus, Hfq stably interacts with base-paired RNA-RNA complexes.

Hfq enhances sRNA-target RNA binding (Møller et al. 2002; Zhang et al. 2002; Afonyushkin et al. 2005; Kawamoto et al. 2006; Soper and Woodson 2008; Holmqvist et al. 2010). We monitored association of the Mic ${ }^{\star}-$ omp RNA pairs $\pm 10 \mathrm{nM} \mathrm{Hfq}_{6}$. From the time courses in Figure $3 \mathrm{~B}$ (and Supplemental Fig. S6C,D), second-order binding rate constants were calculated. In the absence of Hfq, RNA duplex formation was slow $\left(\mathrm{MicA}^{\star}-\mathrm{ompA}\right.$ RNA: $7 \times 10^{4}$ $\left.\mathrm{M}^{-1} \mathrm{sec}^{-1}\right)$, but inclusion of Hfq promoted ternary complex formation within $20 \mathrm{sec}$, which corresponds to an $\approx 50$-fold increase in sRNA-mRNA association rate (MicA ${ }^{\star}-$ ompA RNA: $3.5 \times 10^{6} \mathrm{M}^{-1} \mathrm{sec}^{-1}$; less for MicF-

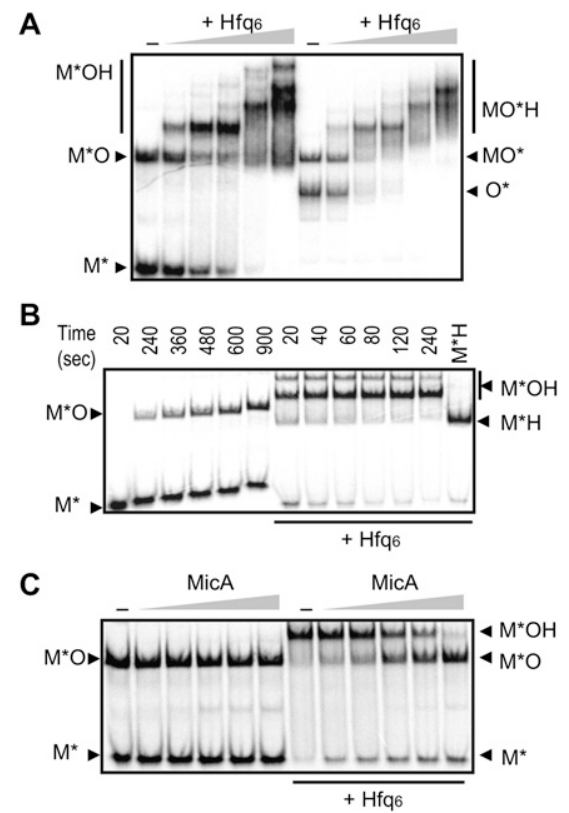

Figure 3. Hfq promotes rapid MicA-ompA RNA base-pairing and forms stable ternary complexes, but is dissociated by excess competitor RNA. (A) Gel-shift assays using MicA* or ompA RNA*, incubated for $15 \mathrm{~min}$ at $37^{\circ} \mathrm{C}$ with $10 \mathrm{nM}$ unlabeled complementary RNA. Increasing concentrations of $\mathrm{Hfq}_{6}$ were included $(1,5,10,20$, and $50 \mathrm{nM}$ ). Samples were run on native gels. Autoradiograms are shown. $\left(\mathrm{M}^{\star}\right.$ and $\left.\mathrm{O}^{\star}\right)$ Labeled MicA, ompA RNA; (MO and $\left.\mathrm{MOH}\right)$ MicA-ompA RNA duplexes and ternary complexes with Hfq, respectively. (B) The kinetics of MicA-ompA RNA interaction were determined from time courses in the absence (left) or presence (right) of $10 \mathrm{nM} \mathrm{Hfq}_{6} . \mathrm{M}^{\star}, \mathrm{M}^{\star} \mathrm{O}$, and $\mathrm{M}^{\star} \mathrm{OH}$ are labeled as in $A$. Hfq-MicA ${ }^{\star}$ complexes $\left(\mathrm{M}^{\star} \mathrm{H}\right)$ were loaded as controls. $(C) \mathrm{MicA}^{\star}-$ ompA RNA duplexes were formed and incubated without or with $10 \mathrm{nM} \mathrm{Hfq}_{6}$ for $15 \mathrm{~min}$ at $37^{\circ} \mathrm{C}$. Increasing concentrations of unlabeled MicA RNA $(0.037,0.075,0.375,0.75$, and $3.75 \mu \mathrm{M})$ were added, and the resulting complexes were analyzed after an additional $15 \mathrm{~min}$ at $37^{\circ} \mathrm{C}$.
ompF) (Supplemental Fig. S6D), in agreement with results reported (Soper and Woodson 2008).

\section{Competitor RNAs readily displace $H f q$ from RNA duplexes}

We asked whether Hfq can be actively displaced from ternary complexes as from binary complexes. Preformed $\mathrm{Mic}^{\star}-\mathrm{omp}$ or $\mathrm{Mic}^{\star}-\mathrm{omp}-\mathrm{Hfq}_{6}$ complexes were competed with increasing concentrations of Mic RNAs, followed by gel-shift analysis (Fig. 3C; Supplemental Fig. S6E,F). These results show that (1) Mic ${ }^{\star}-$ omp complexes formed in the absence of Hfq are stable; even a great molar excess of unlabeled Mic RNA only slightly increases the level of free $\mathrm{Mic}^{\star}$, (2) Hfq increases RNA-RNA association rate rather than prevents dissociation, and $(3)$ increasing concentrations of unlabeled Mic RNAs scavenge Hfq from the ternary complexes, leaving the $\mathrm{Mic}^{\star}$-omp RNA complexes mostly intact.

RNA-driven displacement on ternary complexes was quantitatively assayed by filter binding. Figure 2, E and F, and Table 1 show that ternary complexes were very stable and that dissociation was competitor concentration-dependent (somewhat less effective than on binary complexes). Apparent $k_{\mathrm{d}}$ values ranged from $\approx 0.4 \times 10^{-4} \mathrm{sec}^{-1}$ (no competitor) to $\approx 2.3 \times 10^{-3} \mathrm{sec}^{-1}$ (at $7 \mu \mathrm{M} \mathrm{MicA}$ ), representing a $>50$-fold increase in dissociation rate and a decrease in half-life from $\approx 290$ to $\approx 5 \mathrm{~min}$. Thus, active exchange of ternary complexes contributes to overall cycling.

Cycling occurs in many protein-protein and RNAprotein complexes. However, the realization that cycling occurs does not answer the question of how it works and whether the properties of the mechanism can account for the biological constraints in vivo. The mechanism of cycling of RNAs on Hfq described here is fundamentally different from conventional (passive) cycling. Even though observations in line with ours have been published (e.g., Lease and Woodson 2004; Afonyushkin et al. 2005), previous work did not consider that rapid cycling is promoted by RNA concentration-driven displacement.

It will be a challenge to address the validity of the active cycling model in vivo. Overexpression of an sRNA changes the repertoire of Hfq-associated RNAs (Papenfort et al. 2009), in agreement with our model. We plan to obtain more quantitative data on Hfq-bound/free RNAs under sRNA induction conditions and address cycling kinetics in vivo. Finally, it is tempting to speculate that cycling of RNA on eukaryotic Lsm proteins follows the model proposed in this study.

\section{Materials and methods}

\section{Chemicals, reagents, and oligodeoxyribonucleotides}

Chemicals and reagents were purchased from Sigma-Aldrich or GE Healthcare. Oligodeoxyribonucleotides (Supplemental Table S3), poly-A, and poly-U RNAs were from Sigma-Genosys.

\section{Purification of $\mathrm{Hfq}$}

Purification of His6-tagged Hfq from E. coli strain BL21(DE3)pLys with plasmid pTE607 (a kind gift of Thomas Elliott, West Virginia Science Center) is described in detail in the Supplemental Material. The final Hfq fractions were stored in buffer A $50 \mathrm{mM}$ Tris- $\mathrm{HCl}$ at $\mathrm{pH} 7.5,1 \mathrm{mM}$ EDTA, $5 \%$ glycerol) $+50 \mathrm{mM} \mathrm{NH}_{4} \mathrm{Cl}$ and $0.1 \%$ Triton X-100 at $4^{\circ} \mathrm{C}$. Hfq concentrations are given as hexamers throughout this paper. 
Fender et al.

\section{RNA synthesis and labeling}

The ompA, ompC, and ompF RNAs comprise the 5'-most 172, 216, and 214 nucleotides of the three mRNAs, respectively. All RNAs were transcribed from PCR-generated DNA templates carrying a T7 promoter. For primers, see Supplemental Table S3. In vitro RNA synthesis was done by T7 RNA polymerase (Ambion), and purification of the RNAs followed the protocols described (Darfeuille et al. 2007). When applicable, RNAs were dephosphorylated and 5 -end-labeled with $\gamma-\left[{ }^{33}\right.$ P]ATP or $\gamma-\left[{ }^{32}\right.$ P]ATP (PerkinElmer).

\section{Gel mobility shift assays}

Gel mobility shift assays were carried out with in vitro transcribed RNAs and preparations of Hfq in TMN buffer $(20 \mathrm{mM}$ Tris-acetate at $\mathrm{pH} 7.6$, $100 \mathrm{mM} \mathrm{Na}$-acetate, $5 \mathrm{mM} \mathrm{Mg}_{2}$-acetate) for $5 \mathrm{~min}$ at $37^{\circ} \mathrm{C}$. For details on the specific conditions used, and on gel analyses and calculations, see the Supplemental Material.

\section{Filter binding assays}

Reactions conditions and buffers were as described for gel-shift assays, and details of the assay protocol can be found in the Supplemental Material.

\section{Acknowledgments}

We acknowledge support from the Swedish Research Council and the European Commission (EU-STREPs BacRNA and FOSRAK) to E.G.H.W., and from FOSRAK to B.Z. J.F. is supported by an ERC grant. A.F. is a Marie Curie Fellow (EIF RNAREG).

\section{References}

Afonyushkin T, Vecerek B, Moll I, Bläsi U, Kaberdin VR. 2005. Both RNase E and RNase III control the stability of sodB mRNA upon translational inhibition by the small regulatory RNA RyhB. Nucleic Acids Res 33: 1678-1689.

Altuvia S, Weinstein-Fischer D, Zhang A, Postow L, Storz G. 1997. A small, stable RNA induced by oxidative stress: Role as a pleiotropic regulator and antimutator. Cell 90: 43-53.

Andersen J, Delihas N. 1990. micF RNA binds to the $5^{\prime}$ end of ompF mRNA and to a protein from Escherichia coli. Biochemistry 29: 9249-9256.

Arluison V, Folichon M, Marco S, Derreumaux P, Pellegrini O, Seguin J, Hajnsdorf E, Regnier P. 2004. The C-terminal domain of Escherichia coli Hfq increases the stability of the hexamer. Eur J Biochem 271: 1258-1265.

Brennan RG, Link TM. 2007. Hfq structure, function and ligand binding. Curr Opin Microbiol 10: 125-133.

Chen S, Zhang A, Blyn LB, Storz G. 2004. MicC, a second small-RNA regulator of Omp protein expression in Escherichia coli. I Bacteriol 186: 6689-6697.

Darfeuille F, Unoson C, Vogel J, Wagner EGH. 2007. An antisense RNA inhibits translation by competing with 'standby' ribosomes. Mol Cell 26: $381-392$.

de Haseth PL, Uhlenbeck OC. 1980a. Interaction of Escherichia coli host factor protein with oligoriboadenylates. Biochemistry 19: 6138-6146.

de Haseth PL, Uhlenbeck OC. 1980b. Interaction of Escherichia coli host factor protein with $Q \beta$ ribonucleic acid. Biochemistry 19: 6146-6151.

Franze de Fernandez MT, Eoyang L, August JT. 1968. Factor fraction required for the synthesis of bacteriophage Q $\beta$-RNA. Nature 219: 588-590.

Geissmann TA, Touati D. 2004. Hfq, a new chaperoning role: Binding to messenger RNA determines access for small RNA regulator. $E M B O J$ 23: 396-405.

Holmqvist E, Reimegård J, Sterk M, Grantcharova N, Römling U, Wagner EGH. 2010. Two antisense RNAs target the transcriptional regulator CsgD to inhibit curli synthesis. EMBO I 29: 1803-1816.

Hopkins JF, Panja S, McNeil SA, Woodson SA. 2009. Effect of salt and RNA structure on annealing and strand displacement by Hfq. Nucleic Acids Res 37: 6205-6213.

Kawamoto H, Koide Y, Morita T, Aiba H. 2006. Base-pairing requirement for RNA silencing by a bacterial small RNA and acceleration of duplex formation by Hfq. Mol Microbiol 61: 1013-1022.

Lease RA, Woodson SA. 2004. Cycling of the Sm-like protein Hfq on the DsrA small regulatory RNA. J Mol Biol 344: 1211-1223.
Link TM, Valentin-Hansen P, Brennan RG. 2009. Structure of Escherichia coli Hfq bound to polyriboadenylate RNA. Proc Natl Acad Sci 106: 19292-19297.

Lorenz C, Gesell T, Zimmermann B, Schoeberl U, Bilusic I, Rajkowitsch L, Waldsich C, von Haesler A, Schroeder R. 2010. Genomic SELEX for Hfq-binding RNAs identifies genomic aptamers predominantly in antisense transcripts. Nucleic Acids Res 35: 3794-3808.

Massé E, Escorcia FE, Gottesman S. 2003. Coupled degradation of a small regulatory RNA and its mRNA targets in Escherichia coli. Genes Dev 17: 2374-2383.

Mikulecky PJ, Kaw MK, Brescia CC, Takach JC, Sledjeski DD, Feig AL. 2004. Escherichia coli Hfq has distinct interaction surfaces for DsrA, rpoS and poly(A) RNAs. Nat Struct Mol Biol 11: 1206-1214.

Møller T, Franch T, Hojrup P, Keene DR, Bachinger HP, Brennan RG, Valentin-Hansen P. 2002. Hfq: A bacterial Sm-like protein that mediates RNA-RNA interaction. Mol Cell 9: 23-30.

Nikulin A, Stolboushkina E, Perederina A, Vassilieva I, Bläsi U, Moll I, Kachalova G, Yokoyama S, Vassylyev D, Garber M, et al. 2005. Structure of Pseudomonas aeruginosa Hfq protein. Acta Crystallogr D Biol Crystallogr 61: 141-146.

Papenfort K, Pfeiffer V, Mika F, Lucchini S, Hinton JC, Vogel J. 2006. $\sigma^{\mathrm{E}}$ dependent small RNAs of Salmonella respond to membrane stress by accelerating global omp mRNA decay. Mol Microbiol 62: 1674-1688.

Papenfort K, Said N, Welsink T, Lucchini S, Hinton JC, Vogel J. 2009. Specific and pleiotropic patterns of mRNA regulation by ArcZ, a conserved, Hfq-dependent small RNA. Mol Microbiol 74: 139-158.

Rajkowitsch L, Schroeder R. 2007. Dissecting RNA chaperone activity. RNA 13: 2053-2060.

Randall LL, Hardy SJ. 1995. High selectivity with low specificity: How SecB has solved the paradox of chaperone binding. Trends Biochem Sci 20: 65-69.

Rasmussen AA, Eriksen M, Gilany K, Udesen C, Franch T, Petersen C, Valentin-Hansen P. 2005. Regulation of ompA mRNA stability: The role of a small regulatory RNA in growth phase-dependent control. Mol Microbiol 58: 1421-1429.

Romby P, Vandenesch F, Wagner EGH. 2006. The role of RNAs in the regulation of virulence-gene expression. Curr Opin Microbiol 9: 229-236.

Sauter C, Basquin J, Suck D. 2003. Sm-like proteins in eubacteria: The crystal structure of the Hfq protein from Escherichia coli. Nucleic Acids Res 31: 4091-4098.

Schumacher MA, Pearson RF, Møller T, Valentin-Hansen P, Brennan RG. 2002. Structures of the pleiotropic translational regulator Hfq and an Hfq-RNA complex: A bacterial Sm-like protein. EMBO J 21: 3546-3556.

Sittka A, Lucchini S, Papenfort K, Sharma CM, Rolle K, Binnewies TT, Hinton JC, Vogel J. 2008. Deep sequencing analysis of small noncoding RNA and mRNA targets of the global post-transcriptional regulator, Hfq. PLoS Genet 4: e1000163. doi: 10.1371/journal.pgen.1000163.

Soper TJ, Woodson SA. 2008. The rpoS mRNA leader recruits Hfq to facilitate annealing with DsrA sRNA. RNA 14: 1907-1917.

Sun X, Wartell RM. 2006. Escherichia coli Hfq binds A18 and DsrA domain II with similar 2:1 Hfq6/RNA stoichiometry using different surface sites. Biochemistry 45: 4875-4887.

Udekwu KI, Darfeuille F, Vogel J, Reimegård J, Holmqvist E, Wagner EGH. 2005. Hfq-dependent regulation of OmpA synthesis is mediated by an antisense RNA. Genes Dev 19: 2355-2366.

Urban JH, Vogel J. 2007. Translational control and target recognition by Escherichia coli small RNAs in vivo. Nucleic Acids Res 35: 1018-1037.

Vecerek B, Rajkowitsch L, Sonnleitner E, Schroeder R, Bläsi U. 2008. The C-terminal domain of Escherichia coli Hfq is required for regulation. Nucleic Acids Res 36: 133-143.

Vecerek B, Beich-Frandsen M, Resch A, Bläsi U. 2010. Translational activation of rpoS mRNA by the non-coding RNA DsrA and Hfq does not require ribosome binding. Nucleic Acids Res 38: 1284-1293.

Wassarman KM, Repoila F, Rosenow C, Storz G, Gottesman S. 2001. Identification of novel small RNAs using comparative genomics and microarrays. Genes Dev 15: 1637-1651.

Waters LS, Storz G. 2009. Regulatory RNAs in bacteria. Cell 136: 615-628.

Zhang A, Wassarman KM, Ortega J, Steven AC, Storz G. 2002. The Smlike Hfq protein increases OxyS RNA interaction with target mRNAs. Mol Cell 9: 11-22.

Zhang A, Wassarman KM, Rosenow C, Tjaden BC, Storz G, Gottesman S. 2003. Global analysis of small RNA and mRNA targets of Hfq. Mol Microbiol 50: 1111-1124. 


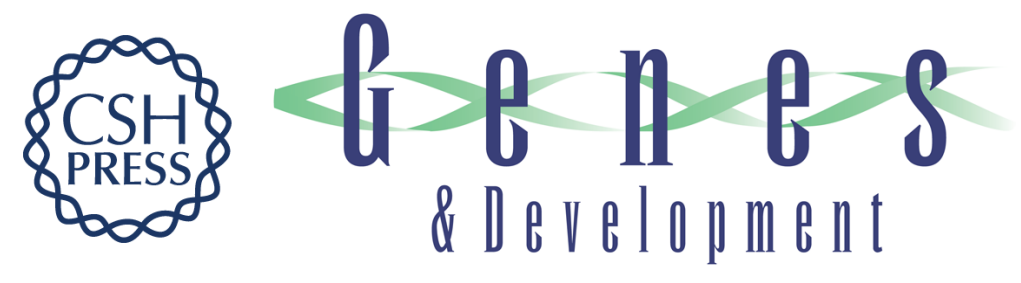

\section{RNAs actively cycle on the Sm-like protein Hfq}

Aurélie Fender, Johan Elf, Kornelia Hampel, et al.

Genes Dev. 2010, 24:

Access the most recent version at doi:10.1101/gad.591310

Supplemental
Material http://genesdev.cshlp.org/content/suppl/2010/11/29/24.23.2621.DC1

References This article cites 40 articles, 9 of which can be accessed free at:

http://genesdev.cshlp.org/content/24/23/2621.full.html\#ref-list-1

License

Email Alerting Receive free email alerts when new articles cite this article - sign up in the box at the top Service right corner of the article or click here.

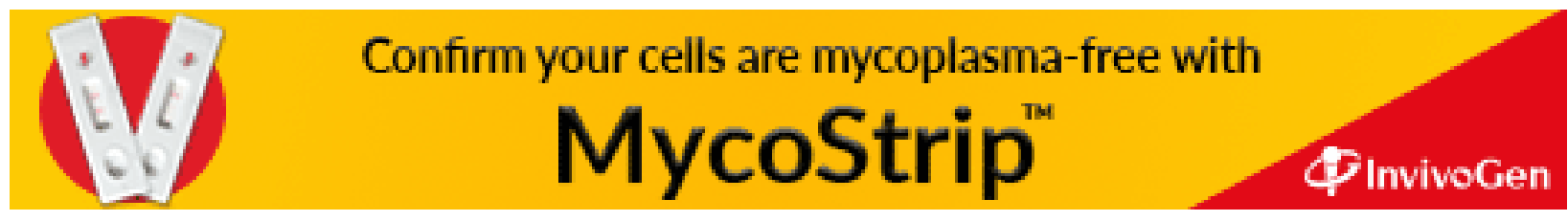

